\title{
LIQUID AND VAPOUR PHASE ANTIBACTERIAL ACTIVITY OF EUCALYPTUS GLOBULUS ESSENTIAL OIL = SUSCEPTIBILITY OF SELECTED RESPIRATORY TRACT PATHOGENS
}

\author{
${ }^{1}$ Boukhatem Mohamed Nadjib, ${ }^{2}$ Ferhat Mohamed Amine, ${ }^{3}$ Kameli Abdelkrim, \\ ${ }^{1}$ Saidi Fairouz and ${ }^{4}$ Mekarnia Maamar \\ ${ }^{1}$ Laboratoire Biotechnologies Végétales, Département de Biologie et Physiologie Cellulaire, \\ Faculté des Sciences de la Nature et de la Vie, Université Blida 1, Blida, Algeria \\ ${ }^{2}$ Département de Chimie, Ecole Normale Supérieure, Vieux-Kouba, Alger, Algeria \\ ${ }^{3}$ Laboratoire éco-Physiologie Végétale, Département Des Sciences Naturelles, \\ Ecole Normale Supérieure, Vieux-Kouba, Alger, Algeria \\ ${ }^{4}$ Société « Extral-Bio » de Productions Des Huiles Essentielles, Route de Chiffa, Blida, Algeria
}

Received 2014-07-24; Revised 2014-07-26; Accepted 2014-08-05

\begin{abstract}
Essential Oils (EO) produced by medicinal plants have been traditionally used for respiratory tract infections and are used nowadays as ethical medicines for colds. Although several studies of Eucalyptus Globulus Labill. Essential Oil (EGEO) have been reported, there are no reports describing vapour activity of EGEO against bacterial respiratory tract pathogens. The aim of this study was to test the efficacy of the Algerian EGEO against some respiratory tract pathogens by disc diffusion and vapour diffusion methods at different concentrations. Chemical composition of the EGEO was analysed by Gas Chromatography-Mass Spectrometry. Fresh leaves of E. globulus on steam distillation yielded $0.96 \%(\mathrm{v} / \mathrm{w})$ of essential oil whereas the analysis resulted in the identification of a total of 11 constituents, 1.8 cineole (85.8\%), $\alpha$-pinene (7.2\%) and $\beta$-myrcene (1.5\%) being the main components. By disc diffusion method, EGEO showed potent antimicrobial activity against Gram-positive more than Gram-negative bacteria. The Diameter of Inhibition Zone (DIZ) varied from $69 \mathrm{~mm}$ to $75 \mathrm{~mm}$ for Staphylococcus aureus and Bacillus subtilis (Gram +) and from 13 to $42 \mathrm{~mm}$ for Enterobacter sp and Escherichia coli (Gram-), respectively. However, the results obtained by both agar diffusion and vapour diffusion methods were different. Significantly higher antibacterial activity was observed in the vapour phase at lower concentrations. A. baumanii and Klebsiella pneumoniae were the most susceptible strains to the oil vapour with DIZ varied from 38 to $42 \mathrm{~mm}$. Therefore, smaller doses of EO in the vapour phase can be inhibitory to pathogenic bacteria. Else, the DIZ increased with increase in concentration of the oil. There is growing evidence that EGEO in vapour phase are effective antibacterial systems and appears worthy to be considered for practical uses in the treatment or prevention of patients with respiratory tract infections or as air decontaminants in hospital. The present study indicates that EGEO has considerable antimicrobial activity, deserving further investigation for clinical applications.
\end{abstract}

Keywords: Eucalyptus Globulus, Essential Oils, Respiratory Tract Pathogens, Antimicrobial Activity, Vapour Phase

Corresponding Author: Boukhatem Mohamed Nadjib, Département de Biologie et Physiologie Cellulaire, Faculté des Sciences de la Nature et de la Vie, Université Blida 1, Blida, Algeria, Tel: 0557.28.30.91 


\section{INTRODUCTION}

Respiratory tract infection is a public health concern in global scale. Most respiratory tract infections are caused by bacterial and viral pathogens responsible for higher mortality and morbidity. Respiratory diseases including allergies, asthma and chronic obstructive pulmonary disease are a major public health burden worldwide (Cermelli et al., 2008).

Most of the developing country still relies primarily on phytotherapy and alternative medicines and generally many people use herbal remedies to treat various respiratory infections. While epidemiology statistics highlight the global and national burden of respiratory diseases, the frequent traditional use of aromatic and medicinal herbs to treat these contaminations requires scientific confirmation and validation (Fabio et al., 2007).

Controlling the number and expansion of pathogens by efficient natural compounds have been the prime targets of research (Mansour et al., 2014). Essential Oils (EO) produced by aromatic and medicinal plants have been habitually used for respiratory tract infections and are used nowadays as ethical medicines for colds (Inouye et al., 2001; Fabio et al., 2007; Cermelli et al., 2008). EOs distillated from a large diversity of herbs have long been used for medicinal purposes. They are potential resource of novel and safe drugs particularly against bacterial pathogens. Scientifically these volatile oils have been proved greatly powerful antimicrobial agents in comparison to antibiotics (Kalemba and Kunicka, 2003). EO usually consists of a large number of components and it is likely that their mode of action involves many targets in bacterial cells. A number of EO components have been recognized as antibacterial such as carvacrol, citral, eucalyptol and thymol (Knobloch et al., 1989; Hammer et al., 1999; Burt, 2004).

African medicinal plants represent a rich but still largely unexploited pool of natural compounds. Numerous countries from the developing world are still dependent on medicinal plants for treating the sick among them. The Algerian climate helps a vast collection of plant species many of which have varied medicinal and antimicrobial potentials (Boukhatem et al., 2011). Traditional herbalist in Algeria uses a variety of herbal mixtures and EO to treat diverse kinds of illnesses including many microbial infections. From ancient times, the leaves of diverse species of Eucalyptus have been used as folk medicines for the treatment of such ailments as colds, toothache, fever and diarrhoea. For example, Eucalyptus globulus has been used as an expectorant.

Numerous varieties of the genus Eucalyptus from the Myrtaceae family are used in Algerian folk medicine for a range of therapy conditions. Eucalyptus Globulus Essential Oils (EGEO) are also widely used in modern cosmetics, food and pharmaceutical industries (Cimanga et al., 2002; Coppen, 2003). EGEO has been used internally for the treatment of influenza, dysentery, articular pain and cystitis and externally for use in the management of erysipelas, dermatitis and burns. In this regard, alcohols monoterpenoid components of the volatile compounds of the EGEO are commercially accessible for the management of the common cold and other symptoms of respiratory tract infections (Cermelli et al., 2008; Elaissi et al., 2012).

Despite the nonexistence of clinical trials to validate the undeniable curative action of EGEO and cineole (major component), both products are ingredients of numerous proprietary drugs in the form of lozenges, nasal drops and preparations for inhalation. The EGEO is widely used for aromatherapy in Europe and Africa (Sulaiman et al., 2014). EGEO has been positioned under Generally Regarded as Safe (GRAS) class by Food and Drug Administration of USA and classified as non-toxic. Even the Council of Europe has accepted use of EGEO as a flavouring agent in foods $(<5 \mathrm{mg} / \mathrm{kg})$ and candies and confectionery items $(<15 \mathrm{mg} / \mathrm{kg}$ ) (Coppen, 2003; Boukhatem et al., 2014). At small amounts, it is also used widely in detergents, soaps and perfumes.

However, the main disadvantage of using EO in liquid phase is that they are more effective antimicrobial when tested in culture and so higher concentrations are required to bring about the same effect. Several approaches have been proposed to minimize EO concentrations. One of them is use of volatile oil in vapour phase to reduce the required quantity. In vapour therapy, EO can be used to help relieve stress, mild depression, anxiety and tension (Lopez et al., 2005; Goni et al., 2009; Tyagi and Malik, 2011).

Although evaluation of EGEO against food spoilage pathogens has been reported, there are no reports describing liquid and vapour activity of RGEO against major bacterial and fungal respiratory tract pathogens.

In the present study, we assessed the antibacterial activity of EGEO against American Type Culture Collection (ATCC) strains and clinical isolates in order to estimate the possibility of using EGEO as an antimicrobial agent to treat or prevent various respiratory tract infections. The activity of a classical antimicrobial drug was compared with the EO susceptibility profile. In addition, we describe the 
identification of the oil constituents by GC/MS analyses, since some of these compounds have been reported to possess antiseptic effects.

\section{MATERIEL AND METHODS}

\subsection{Collection of Plant Material}

Leaves of Eucalyptus globulus Labill., Myrtaceae, were collected in the Eastern part of Ain-Defla (Hammam Righa city), in March 2012, from a single collection site. The leaves were air-dried in the shade at the ambient temperature, protected from the direct light, until further analysis. The identity of the plant specimen was confirmed at the Department of Botany of National Institute of Agronomy (Algiers, Algeria).

\subsection{Extraction of Essential Oil}

Eucalyptus essential oil was distilled from the aerial parts of the plants by steam distillation. The total quantity of fresh plant used varied from 600 to $700 \mathrm{Kg}$. The plant material was encumbered in the still and disposed in layers to allow suitable distribution of the steam.

The process consists of passing water vapour at a low-pressure through a tank (called alembic) filled with aromatic plants. The steam obviously captures the volatile flavors that are enclosed in the plant, who then travel through a cold-water refrigerated serpentine and condense themselves into a liquid. The distillate will have a mix of water vapour and EO which return to their liquid form in the condensing recipient and are separated using a Florentine flask. Both the EO and the water called floral water or hydrosol is retained. The following Fig. 1 summarises the process of Steam distillation. The oils were dried over sodium sulphate and stored in clean brown glass bottles and kept in a controlled temperature chamber, until the time of their analyses. The oil content in the Eucalyptus globulus was determined as percentage yield of oil which was calculated as the percent of the ratio of weight of oil to weight of Eucalyptus leaves.

\subsection{Chemical Analysis}

Qualitative and quantitative data for all the EGEO were performed by Gaz Chromatography (GC) and Gaz Chromatography coupled with the Mass Spectroscopy (GC/MS), respectively.

\subsection{Gas Chromatography}

GC was carried out using Hewlett-Packard (HP) 6890 chromatography apparatus equipped with Flame Ionization Detector (FID) and $(30 \times 0.25 \mathrm{~mm}$ i.d., film thickness $0.25 \mu \mathrm{m}$ ) under the following analytical conditions: Injector and detector temperatures were maintained at 250 and $280^{\circ} \mathrm{C}$, respectively; oven temperature programmed to rise from 45 to $250^{\circ} \mathrm{C}$ at $2^{\circ} \mathrm{C} / \mathrm{min}$, isothermal temperature $45^{\circ} \mathrm{C}$ for $8 \mathrm{~min}$ and $250^{\circ} \mathrm{C}$ for $16 \mathrm{~min}$; the carrier gas was nitrogen with a flow rate of $1.2 \mathrm{~mL} / \mathrm{min}$., the injected volume was 1 $\mu \mathrm{L}$ sample of EGEO.

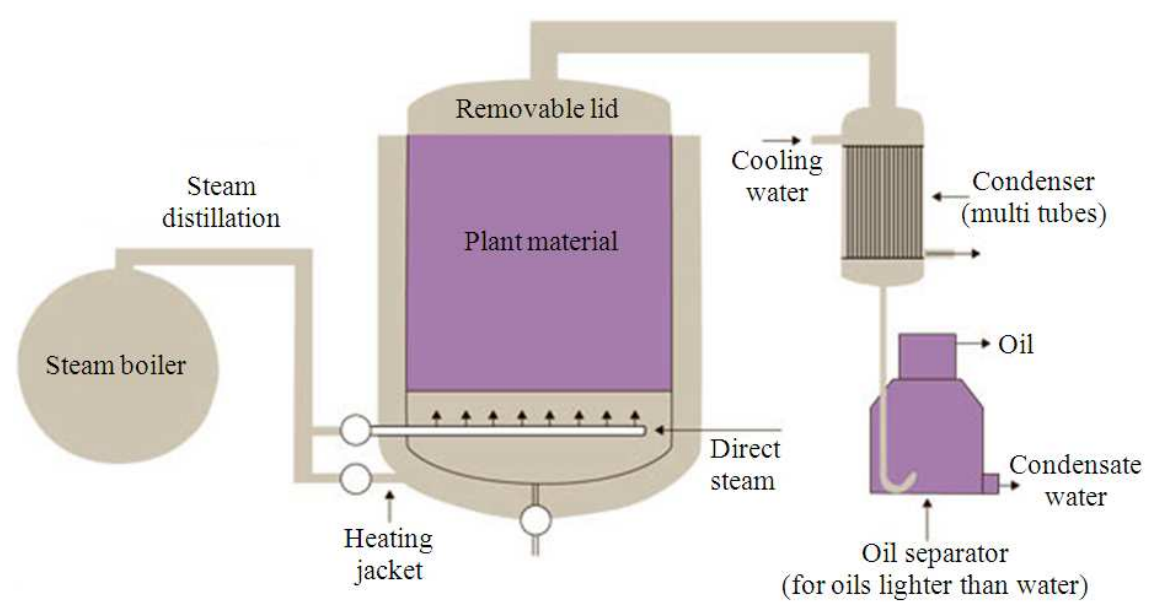

Fig. 1. Steam distillation process with a separate boiler for extraction of Eucalyptus globulus essential oil (http;//www.lneonline.com/articles/201203/onw.) 
Relative concentrations were calculated using the software HP Chemstation, which allows the assimilation of the percentages of the peak areas to the percentages of the various constituents. Retention Indices were obtained by running a series of aliphatic hydrocarbons (C6-C28) by increasing the number of carbon atoms in the GC HP-5MS column).

\subsection{Gas Chromatography-Mass Spectrometry}

The chemical analysis of the essential oil was carried out using a HP 5890 series II Gas Chromatography apparatus equipped with a apolar column HP-5MS $(30 \times 0.25 \mathrm{~mm}$ i.d., film thickness $0.25 \mu \mathrm{m})$ and 5972 mass selective detectors. Helium was used as the carrier gas. The mass spectrometer operating conditions were: Ionisation voltage, $70 \mathrm{eV}$, ion source $230^{\circ} \mathrm{C}$. The GC/MS parameters were identical to those for the GC analysis.

\subsection{Compound Identification}

The identification of the compounds was based on the comparison of their Retention Index and of the mass spectra with those of authentic compounds by means of Wiley 275 databases and with the literature data) (Adams, 2001).

\subsection{Antibacterial Testing}

Antibacterial activity of RGEO in liquid and vapour phase were determined by disc diffusion and disc volatilization method, respectively (Tyagi and Malik, 2011).

\subsection{Bacterial Strains}

The bacterial strains used in the present study were 20 clinical bacterial isolates ( 7 gram-positive bacteria and 13 Gram-negative strains). These isolates were from respiratory tract specimens (throat swab, pus and bronchial wash) or blood collected from patients who had respiratory symptoms at Boufarik Hospital (Blida, Algeria). Although many of the pathogens tested during the current study are not the only causes of respiratory infections, most of them are known to cause respiratory infections specifically in people with compromised immune systems. All the strains were grown on MuellerHinton Agar (MHA) for bacteria. All medium (MHA) were purchased from Pasteur Institute of Algeria (IPA, Algiers, Algeria). Inoculums were prepared in sterile saline water from 24 and $48 \mathrm{~h}$ cultures of bacteria.

Further, such inoculum was standardized against 0.5 McFarland to acquire microbial suspension including approximately $10^{8} \mathrm{CFU} \mathrm{mL} \mathrm{m}^{-1}$ of microorganism strain.

\subsection{Disc Diffusion Method}

The agar disc diffusion method (Fig. 2), which is normally used as a preliminary check, was employed for the screening of antimicrobial activities of the volatile oil. All tested bacterial strains were maintained on an agar slant and stored at $25^{\circ} \mathrm{C}$. Microbial media used for culture and multiplication of tested strains was MHA.

Inoculum of each strain to be tested was prepared with fresh cultures by suspending the microorganisms in sterile saline $(0.9 \% \mathrm{NaCl})$ and adjusting the density to $0.5 \mathrm{Mc}$ Farland standard $\left(10^{8} \mathrm{CFU} \mathrm{mL}^{-1}\right)$ using Densimat (BioMérieux, France). In the first step, antibacterial effect of EGEO was investigated by the disc diffusion method. Antibiotic discs of Ampicillin (AMP, $10 \mu \mathrm{g}$ ), Ciprofloxacin (CIP, 5 $\mathrm{g}$ ), Amoxicillin (AML10,

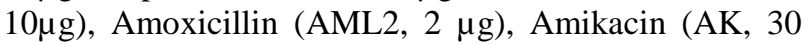
$\mu \mathrm{g})$, Gentamicin (GC, $30 \mu \mathrm{g}$ ), Penicillin G (P, $10 \mathrm{UI})$, Oxacillin (OXA, $1 \mu \mathrm{g}$ ) and Ticarcillin (TIC, $75 \mu \mathrm{g}$ ) (Bio Rad Laboratories, France) were used in order to control the sensitivity of tested clinically isolated microorganisms strains. Discs without samples were used as a negative control. Filter paper discs $(9 \mathrm{~mm}$ in diameter, Schleicher and Schull GmbH, Dassel, Germany) were impregnated with 3 different volumes (20, 40 and $60 \mu \mathrm{L}$ per disc) of EGEO and placed on the inoculated plates (MHA). After maintaining at room temperature for $30 \mathrm{~min}$, the plates were incubated under aerobic conditions at $37^{\circ} \mathrm{C}$ for $48 \mathrm{~h}$. Antibacterial activity was assessed by measuring the Diameter of the Inhibition Zone (DIZ) in millimeters (including disc diameter of $9 \mathrm{~mm}$ ) for the test strains comparing to the controls.

\subsection{Vapor Diffusion Method}

The antimicrobial property of EGEO in vapour phase was investigated by disc volatilization technique (Fig. 3) at three different doses $(20,40$ and $60 \mu \mathrm{L}$ per disc). In brief, solidified medium was inoculated over the surface of MHA with $0.1 \mathrm{~mL}$ of suspension of the microbial strains under study and allowed to dry. A paper disc (diameter $9 \mathrm{~mm}$, Schleicher and Schull GmbH, Dassel, Germany) was laid on the inside surface of the upper lid and $20 \mu \mathrm{L}$ of EGEO was positioned on each disc. The plate inoculated was instantly inverted on top of the lid and conserved with parafilm to avoid escape of the essential oil vapour. Plates were incubated at $37^{\circ} \mathrm{C}$ for $48 \mathrm{~h}$. The microbial inhibitory action of EGEO was calculated by measuring the DIZ of microorganism growth above the disc. Blank discs served as negative control. 


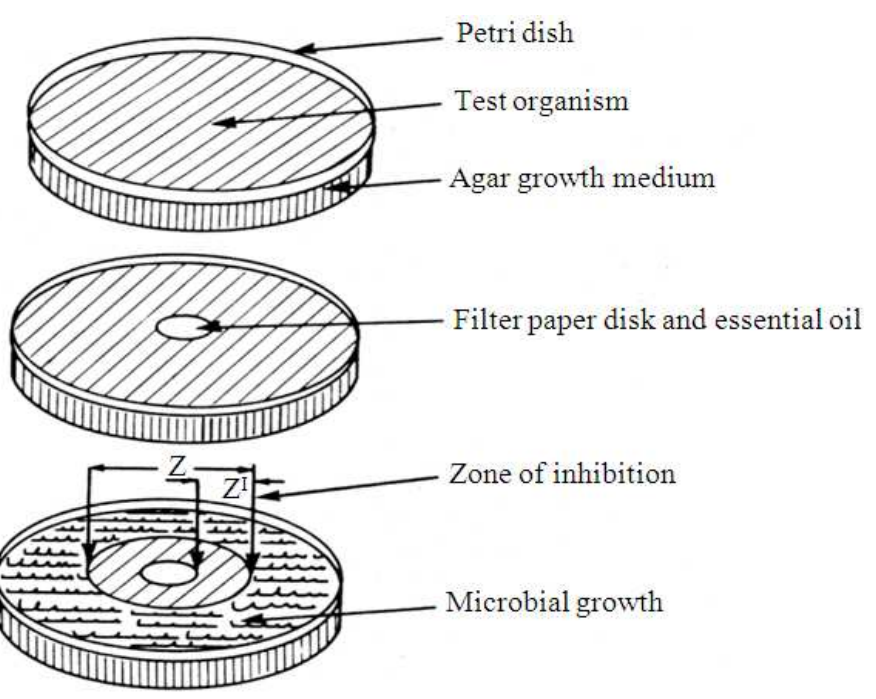

Fig. 2. Determination of the Diameter of Inhibition Zone by the disc diffusion method (Zaika, 1988)
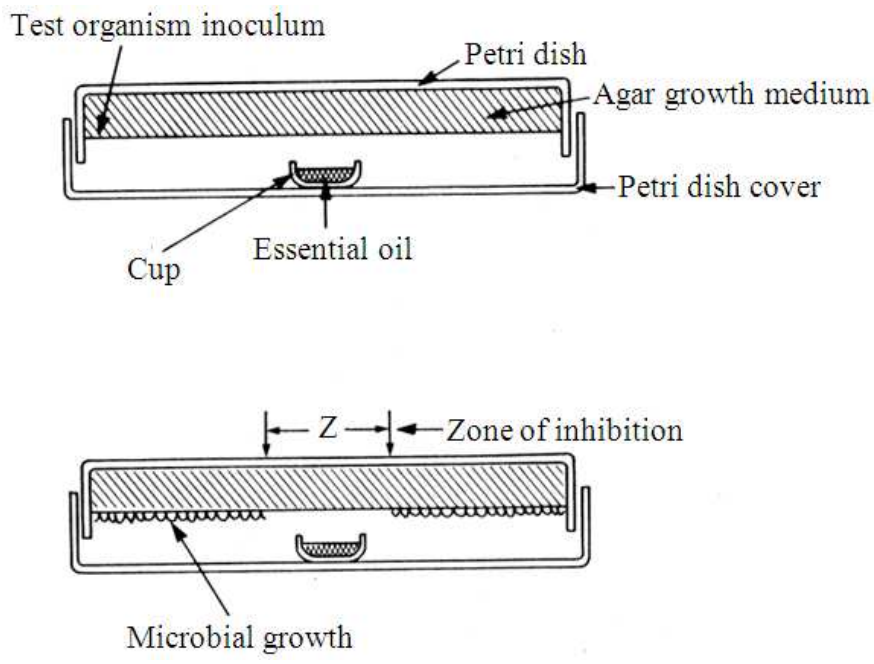

Fig. 3. Determination of the Diameter of Inhibition Zone by Vapour diffusion method (Zaika, 1988)

\section{RESULTS}

\subsection{Chemical Composition of Essential Oil}

The percentage yield of EGEO obtained from the steam distillation procedure of the fresh leaves of $0.96 \%$ (w/w). Determination of the chemical composition of the extracted EO from Eucalyptus globulus was carried out by Gas Chromatography-Mass Spectroscopy. The GC/MS total ion chromatogram of the EGEO was obtained under the conditions described above and the obtained results are seen in Table 1.
GC-MS analyses revealed the presence of 14 compounds representing $90.98 \%$ of the total oil. The major component was 1,8 -cineole $(51.08 \%)$ followed by $\alpha$-pinene (24.6\%), while L-pinocarveol (9.98\%) and globulol (2.81) were minor main components. Other compounds identified in the oil obtained were $\alpha$-terpineol, myrtenol, camphene and cis-carveol. The Eucalyptus oil consisted mostly of oxygenated monoterpenes.

\subsection{Antimicrobial Activity}

The essential oils of Eucalyptus globulus harvested from the Hamma righa region (Ain-Defla, Algeria) 
were evaluated for their antimicrobial activities by disc diffusion and vapour dilution methods against several bacterial isolates.

\subsection{Disc Diffusion Assay}

The agar disc diffusion method is a standard technique extensively used for the fast screening of natural extracts and essential oils for antiseptic effect. The antibacterial activity of EGEO was evaluated in vitro at three different doses. The antimicrobial activity of EGEO, both by direct contact or through vapour phase, was qualitatively and quantitatively assessed by the presence or absence of inhibition zone. The Diameter of the Inhibition Zone (DIZ) is given in Table 2.

Evaluation of DIZ showed that the EGEO was active against all the tested strains (Table 3). Volatile oil of Eucalyptus globulus exhibited significant antimicrobial activity. To the best of our knowledge, the antimicrobial activity of EGEO from Algeria has never been reported. The results obtained from the disc diffusion method (Fig. 4), indicated that the oil exhibited antimicrobial activity against all Gram-positive and 5 Gram-negative bacteria at the concentration of $20 \mu \mathrm{L}$ per disc. EGEO showed little higher antibacterial activity against Escherichia coli ATCC 10536, Staphylococcus aureus, Bacillus subtilis and Acinetobacter baumanii in comparison with reference drug. However, reference antibiotic discs exhibited superior inhibitory activity than of the EGEO against Pseudomonas aeruginosa and Citrobacter freundii. Staphylococcus aureus and Bacillus subtilis were the most vulnerable strains to the EGEO at $60 \mu \mathrm{L}$ per disc. The DIZ varied from $69 \mathrm{~mm}$, as in antibiotical disc zone ranged from $25 \mathrm{~mm}$ and $66 \mathrm{~mm}$.

Among Gram-negative strains, the EGEO was more effective against Escherichia coli, $P$. mirabilis and Acinetobacter baumanii with DIZ measured at $42 \mathrm{~mm}$, $27 \mathrm{~mm}$ and $26 \mathrm{~mm}$ respectively.

\subsection{Vapour Diffusion Method}

Comparative investigations of antibacterial potential of the EGEO were also conducted in the vapour phase by disc volatilization assay (Table 3). As observed in the earlier tests using EGEO in solid agar, the DIZ due to the oil vapour also increased with increasing dose. Therefore, the DIZ due to the EGEO vapour was higher for Gram-positive bacteria than for Gram-negative strains. The DIZ resulting from the exposure to EGEO vapors was significantly larger than that from the same dose of EGEO in the liquid state. This effect was visible at both lower $(20 \mu \mathrm{L})$ and more prominently at higher $(60 \mu \mathrm{L})$ amounts. The volatile oil was also found to inhibit the growth of medically important respiratory pathogens, such as A. baumanii (Fig. 5).

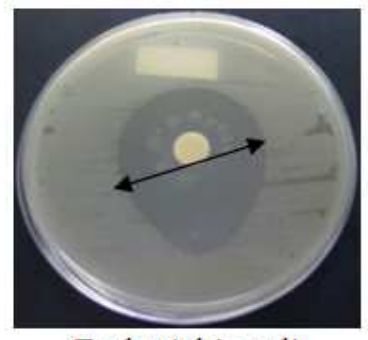

Escherichia coli

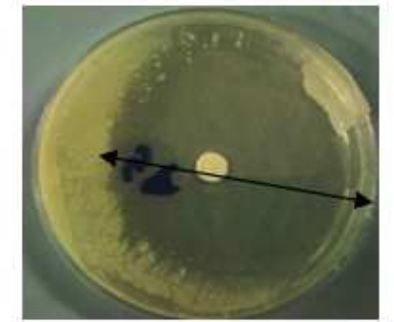

Staphylococcus epidermidis

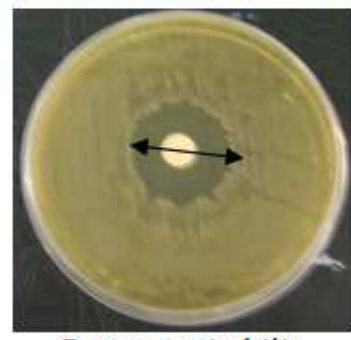

Proteus mirabilis

Fig. 4. Inhibitory effect of Eucalyptus globulus essential oil by disc diffusion method

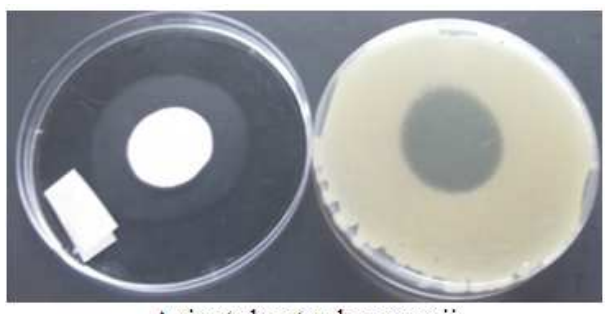

Acinetobacter baumanii

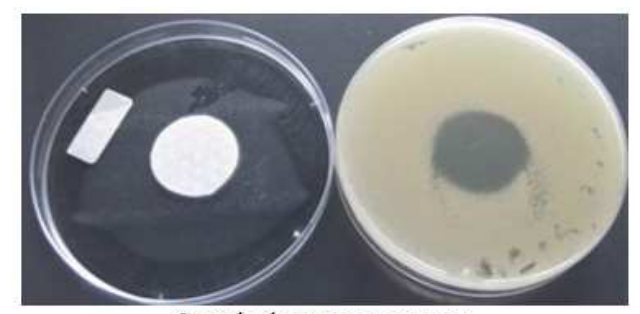

Staphylococcus aureus

Fig. 5. Inhibitory effect of Eucalyptus globulus essential oil by vapour diffusion method 
Table 1. Chemical composition of essential oil from Eucalyptus globulus extracted by steam distillation

\begin{tabular}{lclr}
\hline $\mathrm{N}^{\circ}$ & Retention time $(\mathrm{mn})$ & Compounds* & $(\%)$ \\
\hline 1 & 13.117 & $\alpha$-Pinene & 24.600 \\
2 & 13.517 & Camphene & 0.117 \\
3 & 14.460 & $\beta$-Pinene & 0.217 \\
4 & 16.323 & 1,8 -cineol & 51.083 \\
5 & 17.083 & $\alpha$-Campholenal & 0.390 \\
6 & 18.729 & Fenchol & 0.179 \\
7 & 19.587 & L-pinocarveol & 9.987 \\
8 & 20.233 & Borneol & 0.346 \\
9 & 20.541 & 4 -Terpineol & 0.178 \\
10 & 20.781 & Caren-4-ol & 0.195 \\
11 & 20.907 & $\alpha$-Terpineol & 0.486 \\
12 & 21.044 & Myrtenol & 0.202 \\
13 & 21.850 & Cis-Carveol & 0.187 \\
14 & 30.509 & Globulol & 2.817 \\
& Total identified & & 90.984 \\
\hline
\end{tabular}

Table 2. The main components identified in the Essential oils of Eucalyptus globulus determined by GC-MS

\begin{tabular}{|c|c|c|c|c|c|c|c|c|}
\hline \multirow{4}{*}{$\begin{array}{l}\text { Country } \\
\text { Constituents }\end{array}$} & \multirow[b]{4}{*}{$\mathrm{RI} *$} & \multicolumn{7}{|c|}{ Relative abundance calculated on fresh weight basis (\%) } \\
\hline & & $\begin{array}{l}\text { Mulyaningsih et al. } \\
\text { (2010) }\end{array}$ & $\begin{array}{l}\text { Goldbeck et al } \text {. } \\
\text { (2014) }\end{array}$ & $\begin{array}{l}\text { Vilela et al. } \\
\text { (2009) }\end{array}$ & $\begin{array}{l}\text { Elaissi et al. } \\
\text { (2012) }\end{array}$ & $\begin{array}{l}\text { Manika et al. } \\
\text { (2013) }\end{array}$ & $\begin{array}{l}\text { Kumar et al. } \\
\text { (2012) }\end{array}$ & $\begin{array}{l}\text { Tyagi and } \\
\text { Malik (2011) }\end{array}$ \\
\hline & & Germany & Brazil & Brazil & Tunisia & India & India & India \\
\hline & & & & & & & & \\
\hline$\alpha$-Pinene & 925 & 1.530 & 8.30 & - & 12.0 & 1.2 & - & 4.2 \\
\hline$\beta$ - myrcene & 992 & - & - & 0.49 & - & 0.1 & 1.88 & 1.5 \\
\hline$\alpha$-Phellandrene & 1002 & 2.610 & - & - & - & - & 0.93 & 1.3 \\
\hline Limonene & 1018 & - & - & - & 2.3 & - & 10.09 & 17.8 \\
\hline$p$-Cymene & 1024 & 0.490 & 1.79 & - & 1 & - & - & 9.5 \\
\hline 1,8-Cineole & 1030 & 14.55 & 71.05 & 89.95 & 53.7 & 63.7 & 33.62 & 45.4 \\
\hline$\gamma$-Terpinene & 1057 & 0.180 & - & 0.25 & - & 0.8 & 2.92 & 8.8 \\
\hline Linalool & 1111 & 0.120 & - & - & - & 0.3 & 2.34 & 0.5 \\
\hline Pinocarvone & 1162 & - & 0.75 & 0.3 & 1.7 & - & - & 0.4 \\
\hline Borneol & 1166 & 0.410 & - & - & - & - & - & 0.1 \\
\hline Terpinen-4-ol & 1176 & 1.870 & - & 0.72 & - & 1.4 & 2.42 & 1.4 \\
\hline$\alpha$-Terpineol & 1189 & 0.850 & 0.79 & 0.62 & 3.3 & 0.9 & 4.72 & 3.6 \\
\hline Geraniol & 1252 & Trace & - & - & - & 0.3 & 0.24 & 0.1 \\
\hline Aromadendrene & 1446 & 31.17 & - & - & 3.7 & 13.5 & - & - \\
\hline Viridiflorol & 1593 & 0.240 & - & - & 1.7 & - & - & - \\
\hline Globulol & 1595 & 10.69 & 3.51 & - & 7.0 & 3.4 & - & - \\
\hline
\end{tabular}

(-) Not detected. The values in bold are to highlight the chemical constituents found in higher percentage in the essential oil. *RI: Retention Index (KI) determined on apolar capillary columns using a homologous series of $n$-alkanes hydrocarbons

EGEO showed higher activity in the vapour phase. $B$. subtilis, E. coli and S. epidermidis were the most sensitive bacteria. The growth of $B$. subtilis ATCC 6633 were inhibited semi totally $(50 \mathrm{~mm})$ by the oil vapour at $60 \mu \mathrm{L}$ exposure. To the best of our knowledge, this is the first report demonstrating antimicrobial activity of Algerian EGEO vapour against pathogenic bacteria. The use in vapour phase could have additional advantages such as efficacy without requiring direct contact resulting in ease of application.

\section{DISCUSSION}

1,8-cineole determines the business value of the Eucalyptus oil and its significance as a raw material for diverse industries. Different percentages of 1,8-cineole in 
E. globules leaf oil have been mentioned: $14.55 \%$ in Germany, $71.05 \%$ in Brazil, $53.7 \%$ in Tunisia and $33.6 \%$ to $66.7 \%$ in India (Table 3). The majority volatile oil extracted from E. globulus contains at least $5 \%$ to as high as 95\% 1,8-cineole. Geographical and climatic conditions have been implicated as factors responsible for these variations. Other factors may include time of harvest, age of plant and method of distillation. Although steam and hydro-distillations are the most famous method for extraction, demerit of this technique includes modification of components by auto-oxidation during distillation (Boukhatem et al., 2014).

Our findings are similar to those from (Elaissi et al., 2012; Cimanga et al., 2002), who revealed that the major components of Eucalyptus oils was 1,8-cineole. The chemical profiles of a variety of other Eucalyptus species have been published (Kumar et al., 2012; Manika et al., 2013) and are comparable to our results.

Nevertheless, (Singh et al., 1988) extracted the leaf oil of E. urophylla from India, with $p$-cymene (75.0\%), $\alpha$-pinene $(7.0 \%)$ and $\alpha$-terpinene $(4.0 \%)$ being the main compounds. We suggest that such divergence might also be linked to the differences in the chemo type of trees.

As can be seen from the Table 4, the EGEO showed various degrees of antimicrobial activity depending on the tested bacterial strains. The DIZ increased with the increasing concentration of EO. Thus, the DIZ due to the same concentration of EO was bigger for Gram-positive than for Gram-negative bacteria. Previous studies have reported the high sensitive character of $S$. aureus to essential oils with a high content of $p$-cymene. In addition, other researchers reported that this sensitivity of $S$. aureus was due to the single layer wall of the bacteria (Cimanga et al., 2002).

In yet another screening study, (Tyagi and Malik, 2011) evaluated freshly distilled leaf oils from species of Eucalyptus against Gram-positive and Gram-negative bacteria, some of which were pathogens. The authors confirmed that in general Gram-negative bacteria are less susceptible than Gram-positive ones.

Another screening research, this time involving seventeen Eucalyptus growing in Cuba, had earlier been conducted by (Proenza et al., 2013). Tests were carried out against Gram-positive and Gram-negative bacteria using volatile oils from the following Eucalyptus species. B. subtilis and $S$. aureus were most sensitive to the oils and $P$. aeruginosa least sensitive.

Overall, the EO showed very promising antimicrobial activity. In our study, Gram-positive bacteria are more susceptible than Gram-negative ones which are in accordance with other studies. This may be due to the different nature of cell envelope that makes access to membrane more restricted in Gram negative bacteria. In addition, the periplasmatic space contains enzymes which are capable of breaking down foreign molecules introduced from the outside (Burt, 2004).

In recent years attempts have been made to identify the component (s) of the oils responsible for such bioactivities. The antimicrobial activity of Eucalyptus oils and other volatile oils would be expected to reflect their composition, the structural configuration of the constituents and their functional groups, along with potential synergistic interactions between the constituents (Burt, 2004). Several researchers have reported that the antimicrobial activity of EO is linked to their chemical composition. Our findings are in agreement with those reported in the literature for other Eucalyptus oil rich in 1.8-cineol (eucalyptol) that showed a very strong microbial inhibitory action versus Grampositive bacteria. Essential oil of Eucalyptus species has mostly aromatic oxygenated monoterpenes, 1,8cineole, globulol and Linalool and their activity are often attributed to these compounds. Numerous papers have confirmed the antimicrobial effect of the EO and/or the extracts of different varieties of the genus Eucalyptus rich in monoterpenic alcohols (Tyagi and Malik, 2011; Elaissi et al., 2012).

However, it is problematic to link the antimicrobial activity of a complex mixture (such as essential oil) to particular compounds. The authors (Cimanga et al., 2002) reported no correlation between either 1,8-cineole content or the content of any other constituent and antimicrobial activity and suggested that the observed activity was due to combinations of more than one oil constituent that are specific to each test bacterium.

The antibacterial properties of plant volatile oils have been recognized since antiquity and have been rediscovered in more recent times. Eucalyptus leaf oils have received attention in a number of studies (Elaissi et al., 2012; Proenza et al., 2013).

Our report evidently validates the upper antibacterial effect of EGEO vapour. This could be attributed to the difference in the relative composition of the oil and vapours as the latter must be enriched in terms of its volatile chemical components (Tyagi and Malik, 2011). An additional explanation that has been recommended for the vapour phase being more efficient is that the lipophilic molecules in the aqueous phase associate to form micelles and thus restrain that attachment of the EO to the organism, whereas the vapour phase allows free 
attachment (Inouye et al., 2001). Though, it is unexpected that in spite of well accepted research papers on the antimicrobial potential of EGEO, very little papers exist on the activity of oil vapors.

Doran et al. (2009) exposed that EO vapors inhibited the growth of antibiotic-sensitive and antibiotic-resistant pathogenic microorganism strains, but the effects were changeable depending on the exposure time. The latter, it was recommended, could reduce also airborne contagion. When Enterococcus sp. are exposed to a citrus EO vapour, morphological changes also happen, mutually with an raise in cell permeability, loss of intracellular ATP and a reduce in intracellular $\mathrm{pH}$ (Fisher and Phillips, 2009). When bacteria were exposed to the vapours of $\mathrm{EO}$, the inhibitory actions were obviously diverse from those established by direct contact (Edwards-Jones et al., 2004). A study carried out by (Goni et al., 2009) revealed that inhibitory effect of mixture of clove and cinnamon EO in vapour phase showed superior antibacterial with fewer active concentrations in the vapor phase compared to liquid phase. As well, an essential oil throat spray may be able to prevent nosocomial acquired pneumonia from resistant bacteria in hospitalized patients with respiratory conditions.

The antibacterial activity of fourteen essential oils and their major constituents in the gaseous state were evaluated against four different bacteria by (Inouye et al., 2001). The authors found $H$. Influenzae to be most susceptible to most essential oils examined. The research also indicated that the antibacterial action of essential oils was most effective when at high vapour concentration for a short time.

Inhalation of Eucalyptus sp. essential oil has traditionally been used to treat respiratory tract disorders. Consequently, the scientific interest in this field has been expanding. Some researchers have demonstrated some efficacy of Eucalyptus EO gainst Haemophilus influenzae. Streptococcus pyogenes, S. pneumoniae, S. agalctia, Staphylococcus aureus, P. aeruginosa, K. pneumonia and $H$. influenzae are the most important causes of the respiratory tract infections and the most resistant to antibiotics (Coppen, 2003).

The potential of Eucalyptus oils for use as practical antimicrobial agents remains to be proven. Some results have been encouraging but others have been less so. The variability is as much a reflection of the widely differing conditions, procedures and test organisms used by different workers as it is of the compositional variation in the oils themselves.
The results obtained by both agar diffusion and vapour diffusion methods were different. The effectiveness of the volatile compounds against microbial growth when in direct contact had already been widely reported, although their application in the vapours phase entails a relative innovative approach. These differences may be explained by considering the physicochemical properties of the antimicrobial agents and the culture media and how the contact between the microorganism and the EO. The antimicrobial effect in direct contact experiments is mostly due to the activity of the more hydrophilic (water-soluble) and less volatile substances, whereas an equilibrium is attained during the vapour phase experiments among the volatile compounds released in the headspace (both hydrophilic and hydrophobic) and part of the more hydrophilic ones, absorbed in the agar surface. The disc diffusion method is considered unsuitable in estimating the antimicrobial activity of EO since the active volatile components are likely to be evaporated. The vapour phase experiments are more reliable in determining the antimicrobial activities of EO (Lopez et al., 2005).

Essential oils produced by plants have been traditionally used for respiratory tract infections and are used nowadays as ethical medicines for colds. In the medicinal field, inhalation therapy of EO has been used to treat acute and chronic bronchitis and acute sinusitis. Inhalation of vapours of EO augmented the output of respiratory tract fluid, maintained the ventilation and drainage of the sinuses, had an anti-inflammatory effect on the trachea and reduced asthma (Coppen, 2003).

Even though the antibacterial activities of EO have been reported in the past, the mechanism of action has not been studied in large aspect. Considering the great number of diverse groups of phytochemical components present in EO, it is most probable that their antimicrobial effect is not linked to one precise mechanism but that there are numerous targets in the cell. The mechanisms or locations in the microbial cell thought to be sites of action for EO components are indicated in Fig. 6.

More comprehensive (and standardised) tests of oils from a greater number of Eucalyptus species are needed to determine whether such oils, or formulations containing them, have a major role to play as antimicrobial agents. If they have, then in vivo studies are needed to assess their efficacy under clinical conditions. With an increasing public awareness of 'green issues', plant volatile oils, including those from Eucalyptus, offer a more eco-friendly alternative to conventional formulations in a number of sectors where antimicrobial action is desirable. 


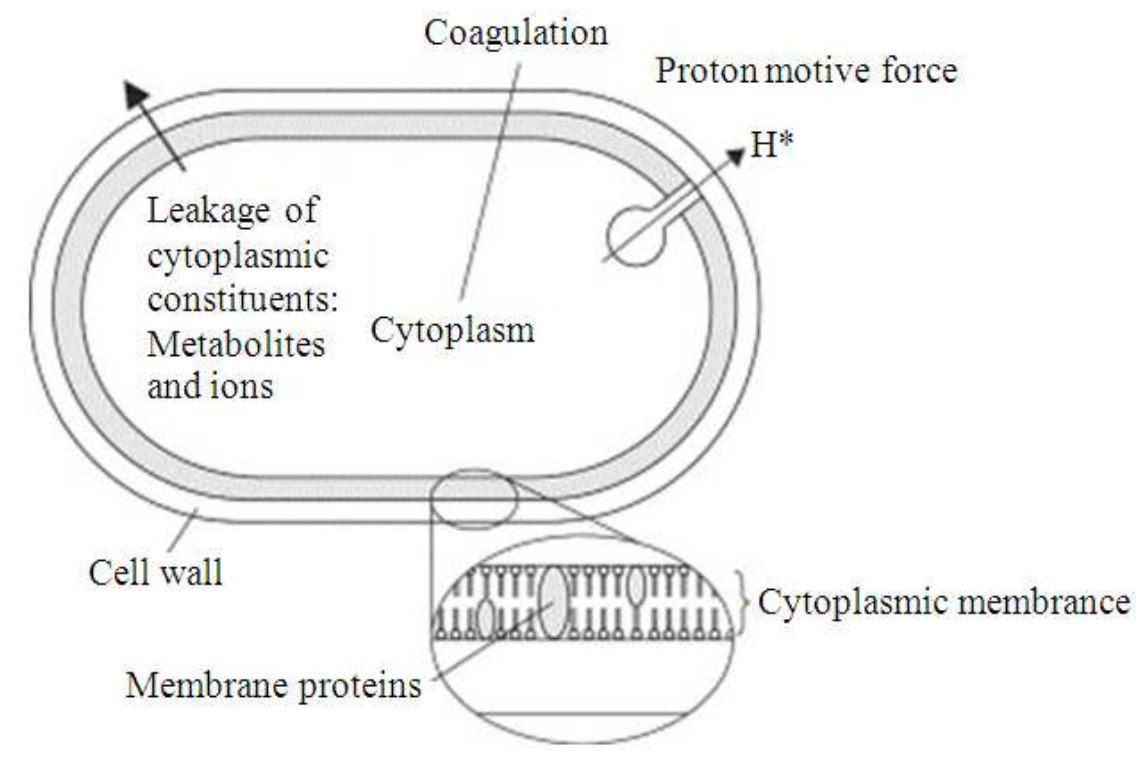

Fig. 6. Locations in the bacterial cell thought to be sites of action for essential oils (Burt, 2004)

Table 3. Susceptibility of the bacteria tested strains to classic antibiotic and to Eucalyptus globulus essential oil

\begin{tabular}{|c|c|c|c|c|c|c|c|c|c|c|c|c|c|c|}
\hline & \multicolumn{14}{|c|}{ Diameter of Inhibition Zone $(\mathrm{mm})^{\mathrm{a}}$} \\
\hline & \multirow{2}{*}{\multicolumn{3}{|c|}{$\begin{array}{l}\text { Disc Diffusion Method } \\
\text { Quantity of EGEO } \\
(\mu \mathrm{L} \text { per disc) }\end{array}$}} & \multirow{2}{*}{\multicolumn{11}{|c|}{$\begin{array}{l}\text { Vapour Diffusion Method } \\
\text { Quantity of EGEO } \\
(\mu \mathrm{L} \text { per disc }) \quad \text { Antibiotic Discs }\end{array}$}} \\
\hline & & & & & & & & & & & & & & \\
\hline & 20 & 40 & 60 & 20 & 40 & 60 & OXA & $\mathrm{P}$ & $\mathrm{GC}$ & AML2 & AML10 & $\mathrm{AK}$ & TIC & CIP \\
\hline \multicolumn{15}{|l|}{ Gram positive strains } \\
\hline \multicolumn{15}{|l|}{ S. aureus } \\
\hline ATCC 6633 & 18.0 & 63.6 & 70.5 & - & 11.2 & 28.0 & $-b$ & 30.0 & 25.6 & & & & & \\
\hline S. Aureus (1) & 15.2 & 29.0 & 69.5 & - & 11.0 & 24.6 & - & 31.0 & 25.0 & & & & & \\
\hline \multicolumn{15}{|l|}{ S. Epidermidis } \\
\hline ATCC 12228 & 14.4 & 20.0 & 65.0 & - & - & 35.0 & - & 29.4 & 26.5 & & & & & \\
\hline \multirow{2}{*}{\multicolumn{15}{|c|}{$\begin{array}{l}\text { S. Epidermiais } \\
\text { B. Subtilis }\end{array}$}} \\
\hline & & & & & & & & & & & & & & \\
\hline ATCC 6633 & 15.4 & 19.0 & 75.0 & 13 & 23.4 & 50.0 & 25.0 & 28.9 & 34.0 & & & & & \\
\hline B. Subtilis & 15.4 & 18.4 & 75.0 & 12 & 23.0 & 42.0 & 25.4 & 28.3 & 36.0 & & & & & \\
\hline \multicolumn{15}{|l|}{ Gram negative strains } \\
\hline S. Typhimurium & - & 19.0 & 32.0 & - & 9.0 & 27.0 & & & & - & 20.0 & 26.0 & & \\
\hline P. Aeruginosa & - & - & - & - & - & - & & & & - & - & 22.0 & & \\
\hline E. Coli ATCC 10536 & 15.2 & 20.4 & 38.0 & 7.6 & 19.8 & 37.0 & 10.0 & - & 30.3 & & & & & \\
\hline E. Coli & 15.2 & 22.4 & 42.0 & 6.8 & 19.0 & 41.0 & 14.0 & - & 30.5 & & & & & \\
\hline K. Pneumonia & 13.0 & 16.0 & 18.0 & - & 13.0 & 42.0 & 12.0 & - & & - & 15.0 & 19.0 & & \\
\hline P. Mirabilis & 12.0 & 18.0 & 27.0 & - & - & 14.0 & & & & - & 20.0 & 21.0 & & \\
\hline C. Freundii & 11.0 & 13.0 & 15.0 & - & - & - & & & & - & 14.0 & 21.0 & & \\
\hline Enterobacter sp. & - & 11.0 & 13.0 & - & 22.0 & 25.0 & & & & - & & & - & - \\
\hline P. Rettgeri & 11.0 & 13.0 & 14.0 & - & 11.0 & 13.0 & & & & - & & & 11.0 & 33.0 \\
\hline A. Baumanii & 14.0 & 22.0 & 26.0 & - & 23.0 & 38.0 & & & & - & 11.0 & - & & \\
\hline
\end{tabular}

${ }^{\mathrm{a}}$ Diameter of Inhibition Zone (mm) including disc diameter of $9 \mathrm{~mm} ;{ }^{\mathrm{b}}$ - no activity. EGEO: Eucalyptus globulus essential oil. Ampicillin (AMP,

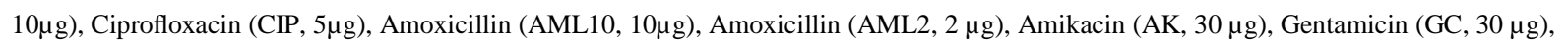
Penicillin G (P, $10 \mathrm{UI})$, Oxacillin (OXA, $1 \mu \mathrm{g}$ ) and Ticarcillin (TIC, $75 \mu \mathrm{g}$ ) were used a positive reference standard for bacterial strains. ATCC: American Type Culture Collection 
Boukhatem Mohamed Nadjib et al. / American Journal of Infectious Diseases 10 (3): 105-117, 2014

Table 4. Antimicrobial activity of essential oils from some Eucalyptus species determined by disc diffusion method

\begin{tabular}{|c|c|c|c|c|c|c|c|}
\hline Country & $\begin{array}{l}\text { Deans and } \\
\text { Ritchie (1987) } \\
\text { UK }\end{array}$ & $\begin{array}{l}\text { Pattnaik et al. } \\
\text { (1997) } \\
\text { India }\end{array}$ & $\begin{array}{l}\text { Cimanga et al. } \\
(2002) \\
\text { Congo }\end{array}$ & $\begin{array}{l}\text { Prabuseenivasan } \text { et al. } \\
\text { (2006) } \\
\text { India }\end{array}$ & $\begin{array}{l}\text { Đakov et al. } \\
\text { (2011) } \\
\text { Serbia }\end{array}$ & $\begin{array}{l}\text { Elaissi } \text { et al. } \\
\text { (2012) } \\
\text { Tunisia }\end{array}$ & $\begin{array}{l}\text { Proenza et al. } \\
\text { (2013) } \\
\text { Cuba }\end{array}$ \\
\hline \multicolumn{8}{|l|}{ Gram (+) strains } \\
\hline S. aureus & $00^{*}$ & 12 & 0.0 & 0.0 & 27 & 9.0 & 23 \\
\hline B. subtilis & 7.5 & - & 21.0 & 0.0 & - & - & 22 \\
\hline E. faecalis & 0.0 & - & - & - & - & 8.7 & - \\
\hline $\begin{array}{l}\text { S. pyogenes } \\
\text { Gram (-) strains }\end{array}$ & - & - & - & - & 28 & - & - \\
\hline P. aeruginosa & 0.0 & 20 & 9.5 & 0.0 & 12 & 8.7 & 10 \\
\hline E. coli & 0.0 & 20 & 15.0 & 8.5 & 28 & 8.0 & 10 \\
\hline K. pneumoniae & 0.0 & 15 & 16.5 & 0.0 & 28 & - & - \\
\hline A. baumannii & - & - & - & - & 25 & - & - \\
\hline P. mirabilis & 0.0 & - & 0.0 & 0.0 & 24 & - & - \\
\hline C. freundii & & 15 & 7.0 & - & 29 & - & - \\
\hline
\end{tabular}

*Diameter of Inhibition Zone (mm); (-) Not determined

\section{CONCLUSION}

Our results demonstrated that EGEO exhibited significant antimicrobial activity against a range of pathogenic bacteria. Moreover, these findings suggest that this oil is highly effective in vapour phase. There is growing evidence that EGEO in vapour phase is effective antimicrobial systems and appears worthy to be considered for practical uses in the treatment or prevention of respiratory tract infections. Additional investigations on curative claims of Eucalyptus volatile oils are needed to investigate these issues and to complement the considerable number of analytical and in vitro bioactivity researches that are being carried out on these natural fragrances.

\section{ACKNOWLEDGMENT}

Special thanks to the team of laboratory of bacteriology (Boufarik Hospital, Blida, Algeria) for providing helpful feedback.

\section{REFERENCES}

Adams, R.P., 2001. Identification of Essential Oil Components by Gas Chromatography/Quadrupole Mass Spectroscopy. 3rd Edn., Allured Pub. Corporation, Carol Stream, ISBN-10: 0931710855, pp: 456.

Boukhatem, M.N., F. Saidi, M.S. Hamaidi, Y. Hakim and M. Mekarnia, 2011. Culture et exploitation industrielle du géranium rosat (Pelargonium graveolens) en Algérie: Etat des lieux et perspectives. Phytothérapie, 9: 304-309. DOI: 10.1007/s10298-011-0635-4
Boukhatem, M.N., M.A. Ferhat, A. Kameli, F. Saidi and M.S. Bozian et al., 2014. Quality assessment of the essential oil from Eucalyptus globulus Labill of Blida (Algeria) origin. Int. Lett. Chem., Phys. Astronomy, 17: 303-315.

Burt, S., 2004. Essential oils: Their antibacterial properties and potential applications in foods-a review. Int. J. Food Microbiol., 94: 223-253. DOI: 10.1016/j.ijfoodmicro.2004.03.022

Cermelli, C., A. Fabio, G. Fabio and P. Quaglio, 2008. Effect of Eucalyptus essential oil on respiratory bacteria and viruses. Current Microbiol., 56: 89-92. DOI: $10.1007 / \mathrm{s} 00284-007-9045-0$

Cimanga, K., K. Kambu, S. Apers and A.J. Vlietinck, 2002. Correlation between chemical composition and antibacterial activity of essential oils of some aromatic medicinal plants growing in the Democratic Republic of Congo. J. Ethnopharmacol., 79: 213-220. DOI: 10.1016/S0378-8741(01)00384-1

Coppen, J.J.W., 2003. Eucalyptus: The Genus Eucalyptus. 1st Edn., CRC Press, London, ISBN-10: 0203219430, pp: 464.

Đakov, T., 2011. Antimicrobial effect of essential oil isolated from Eucalyptus globulus Labill. From Montenegro. Czech J. Food Sci., 29: 277-284. DOI: 10.1080/14786410701592745

Deans, S.G. and G. Ritchie, 1987. Antibacterial properties of plant essential oils. Int. J. Food Microbiol., 5: 165180. DOI: 10.1016/0168-1605(87)90034-1

Doran, A.L., W.E. Morden, K. Dunn and V. Edwards-Jones, 2009. Vapour-phase activities of essential oils against antibiotic sensitive and resistant bacteria including MRSA. Lett. Applied Microbiol., 48: 387-392. DOI: $10.1111 / \mathrm{j} .1472765 X .2009 .02552 . \mathrm{x}$ 
Edwards-Jones, V., R. Buck, M.M. Dawson and K. Dunn, 2004. The effect of essential oils on methicillin-resistant Staphylococcus aureus using a dressing model. Burns, 30: 772-777. DOI: $10.1111 / \mathrm{j} .1472-765 X .2009 .02552 . x$

Elaissi, A., Z. Rouis, S. Mabrouk and F. HarzallahSkhiri, 2012. Correlation between chemical composition and antibacterial activity of essential oils from fifteen Eucalyptus species growing in the Korbous and Jbel Abderrahman Arboreta (North East Tunisia). Molecules, 17: 3044-3057. DOI: 10.3390/molecules17033044

Fabio, A., C. Cermelli, G. Fabio, P. Nicoletti and P. Quaglio, 2007. Screening of the antibacterial effects of a variety of essential oils on microorganisms responsible for respiratory infections. Phytotherapy Res., 21: 374-377. DOI: 10.1002/ptr.1968

Fisher, K. and C. Phillips, 2009. The mechanism of action of a citrus oil blend against Enterococcus faecium and Enterococcus faecalis. J. Applied Microbiol., 106: 1343-1349. DOI: $10.1111 / \mathrm{j} .13652672 .2008 .04102 . x$

Goldbeck, J.C., J.E. Do Nascimento, R.G. Jacob and W.P. Da Silva, 2014. Bioactivity of essential oils from Eucalyptus globulus and Eucalyptus urograndis against planktonic cells and biofilms of Streptococcus mutans. Industrial Crops Products, 60: 304-309. DOI: 10.1016/j.indcrop.2014.05.030

Goni, P., P. López, C. Sánchez, R. Gómez-Lus and R. Becerril, 2009. Antimicrobial activity in the vapour phase of a combination of cinnamon and clove essential oils. Food Chemi., 116: 982-989. DOI: 10.1016/j.foodchem.2009.03.058

Hammer, K.A., C.F. Carson and T.V. Riley, 1999. Antimicrobial activity of essential oils and other plant extracts. J. Applied Microbiol., 86: 985-990. DOI: 10.1046/j.1365-2672.1999.00780.x

Inouye, S., T. Takizawa and H. Yamaguchi, 2001. Antibacterial activity of essential oils and their major constituents against respiratory tract pathogens by gaseous contact. J. Antimicrobial Chemotherapy, 47:

565-573. DOI: $10.1093 / \mathrm{jac} / 47.5 .565$

Kalemba, D. and A. Kunicka, 2003. Antibacterial and antifungal properties of essential oils. Current Med. Chem., 10: 813-829.

DOI: $10.2174 / 0929867033457719$
Knobloch, K., A. Pauli, B. Iberl, H. Weigand and N. Weis, 1989. Antibacterial and antifungal properties of essential oil components. J. Essential Oil Res., 1: 119-128. DOI: 10.1080/10412905.1989.9697767

Kumar, P., S. Mishra, A. Malik and S. Satya, 2012. Compositional analysis and insecticidal activity of Eucalyptus globulus (family: Myrtaceae) essential oil against housefly (Musca domestica). Acta Tropica, 122: 212-218. DOI: 10.1016/j.actatropica.2012.01.015

Lopez, P., C. Sanchez, R. Batlle and C. Nerin, 2005. Solid-and vapor-phase antimicrobial activities of six essential oils: Susceptibility of selected foodborne bacterial and fungal strains. J. Agric. Food Chem., 53: 6939-6946. DOI: 10.1021/jf050709v

Manika, N., C.S. Chanotiya, M.P.S. Negi and G.D. Bagchi, 2013. Copious shoots as a potential source for the production of essential oil in Eucalyptus globulus. Industrial Crops Products, 46: 80-84. DOI: 10.1016/j.indcrop.2013.01.016

Mansour, A.M.A., H.M. Zaki, N.A. Hassan and N.A.M. El-Nashar, 2014. Phenotyping, virulence characteristics of Aeromonas species and the effects of essential plant oils as antimicrobial agents against pathogenic isolates from different sources. Am. J. Infectious Diseases, 10: 21-35. DOI: 10.3844/ajidsp.2014.21.35

Mulyaningsih, S., F. Sporer, S. Zimmermann, J. Reichling and M. Wink, 2010. Synergistic properties of the terpenoids aromadendrene and 1,8-cineole from the essential oil of Eucalyptus globulus against antibiotic-susceptible and antibiotic-resistant pathogens. Phytomedicine, 17: 1061-1066. DOI: 10.1016/j.phymed.2010.06.018

Pattnaik, S., V.R. Subramanyam, M. Bapaji and C.R. Kole, 1997. Antibacterial and antifungal activity of aromatic constituents of essential oils. Microbios, 89: 39-46. PMID: 9218354

Prabuseenivasan, S., M. Jayakumar and S. Ignacimuthu, 2006. In vitro antibacterial activity of some plant essential oils. BMC Complementary Alternative Med., 6: 39-39. DOI: 10.1186/1472-6882-6-39

Proenza, Y.G., Y.V. Tamayo, M.A. Saavedra, Y.S. Garcia and R.H. Espinosa, 2013. Chemical composition and antibacterial activity of the essential oil from Eucalyptus pellita F. Muell. J. Med. Plants Res., 7: 1979-1983. DOI: 10.5897/JMPR12.349 
Singh, A.K., J.J. Brophy and K.C. Gupta, 1988. The essential oil of eucalyptus urophylla a rich source of p cymene. Ind. Perfumer, 32: 201-204.

Sulaiman, G.M., T.R. Marzoog, W.H. Mohammed and R. Bagnati, 2014. Chemical composition, antimicrobial, antioxidant and cytotoxic activities of Eucalyptus chapmaniana grown in Iraq. Am. J. Agric. Biological Sci., 9: 78-88. DOI: $10.3844 / a j a b s s p .2014 .78 .88$

Tyagi, A.K. and A. Malik, 2011. Antimicrobial potential and chemical composition of Eucalyptus globulus oil in liquid and vapour phase against food spoilage microorganisms. Food Chem., 126: 228235. DOI: $10.1016 /$ j.foodchem.2010.11.002
Vilela, G.R., De G.S. Almeida and E.M. Da Gloria, 2009. Activity of essential oil and its major compound, 1, 8-cineole, from Eucalyptus globulus Labill., against the storage fungi Aspergillus flavus Link and Aspergillus parasiticus Speare. J. Stored Products Res., 45:108-111. DOI: 10.1016/j.jspr.2008.10.006

Zaika, L.L., 1988. Spices and herbs: Their antimicrobial activity and its determination1. J. Food Safety, 9: 97-118. DOI: 10.1111/j.1745-4565.1988.tb00511.x 